\title{
The role of relational governance in innovation platform growth: the context of living labs
}

\author{
Chiara Luisa Cantù \\ Università Cattolica del Sacro Cuore, Milano, Italy \\ Daniel Schepis \\ The University of Western Australia, Perth, Australia, and \\ Roberto Minunno and Greg Morrison \\ Curtin University, Perth, Australia
}

\begin{abstract}
Purpose - This paper aims to investigate the role of relational governance in innovation platform development, specifically investigating the context of living labs.

Design/methodology/approach - Two longitudinal case studies are presented, derived from auto-ethnographic narratives, qualitative interviews and secondary documents, which cover the critical stages in the development of each living lab.

Findings - Empirical insights demonstrate the relevance of coordination activities based on joint planning and activities to support innovation platform development across different stages. The governance role of research actors as platform activators is also identified.

Practical implications - The paper offers a useful perspective for identifying collective goals between living lab actors and aligning joint activities across different stages of living lab development.

Social implications - The case provides insights into the challenges and opportunities for collaboration between academia, industry and users to support sustainable construction innovation.

Originality/value - A relational governance mode is identified, going beyond top down or bottom up approaches, which contributes a new understanding of how collective goals align within a relational space.
\end{abstract}

Keywords Sustainability, Circular economy, Inter-organizational relationships, Relational governance, Living lab, Innovation platform

Paper type Research paper

\section{Introduction}

The innovation platform perspective has been investigated across various domains, such as business strategy (Sawhney, 1998), new product development (Pekkarinen and Ulkuniemi, 2008) and open innovation (Isckia and Lescop, 2015). A key aspect within these perspectives is that the platform, considered a technology or medium, provides an environment "that companies can transfer knowledge to, and use the set of building blocks or subsystems and interfaces provided by the external partners to create complementary products or services" (Wang et al., 2021, p. 256). However, simply initiating or activating a platform is not enough to expect its development; attention must be given to relationships within the platform and to the forms of governance applied across its evolution. Governance within this context refers to "the manner in which the decisions in the innovation process are made" (Westerlund et al., 2018, p. 54). This paper examines the role of relational governance in the growth of living lab innovation platforms.

The current issue and full text archive of this journal is available on Emerald Insight at: https://www.emerald.com/insight/0885-8624.htm

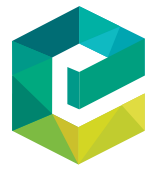

Journal of Business \& Industrial Marketing 36/13 (2021) 236-249

Emerald Publishing Limited [ISSN 0885-8624] [DOI 10.1108/JBIM-02-2020-0114]
Living labs offer an ideal setting for considering how relational governance may impact on innovation platform development. Although there is an absence of one commonly accepted definition, we considered living labs as a sociotechnical platform that organizes its stakeholders into an innovation ecosystem (Westerlund et al., 2018). The combination of diverse stakeholders with sometimes divergent goals can make relational governance a difficult task within living labs. This aligns with debates about whether living labs can truly sustain innovation outcomes for all parties as intended or whether the interests of certain stakeholders may dominate (Hagy et al., 2017).

Previous studies suggest that lead or hub firms can orchestrate and control the participants, thereby defining the goals for the platform (Nambisan and Sawhney, 2011).

\footnotetext{
(C) Chiara Luisa Cantù, Daniel Schepis, Roberto Minunno and Greg Morrison. Published by Emerald Publishing Limited. This article is published under the Creative Commons Attribution (CC BY 4.0) licence. Anyone may reproduce, distribute, translate and create derivative works of this article (for both commercial and non-commercial purposes), subject to full attribution to the original publication and authors. The full terms of this licence may be seen at http://creativecommons.org/licences/by/4.0/ legalcode
}

Received 21 February 2020

Revised 13 August 2020

18 December 2020

31 March 2021

Accepted 5 April 2021 
Yet, control may be insufficient or ineffective in managing relationships between the platform's actors, typically characterized by heterogeneous resources and goals (Håkansson et al., 2009). Alternative perspectives suggest the management of heterogeneous goals requires a more open approach, considering that "unilateral action by any firm to dominate a business network will disrupt the multilateral potential of that network" (Ballantyne and Williams, 2008, p. 98). Following this, the coordination of inter-organizational relationships can be achieved through relational governance involving norms and joint actions. In this context, we examine the following questions:

Q1. How do governance approaches influence the growth of innovation platforms?

Q2. Which activities characterize the relational governance approach of platform activators?

This paper investigates the development of two universityinitiated living labs focusing on sustainability in the construction industry. Two longitudinal case studies are presented, derived from auto-ethnographic narratives, qualitative interviews and secondary documents, which cover the critical stages in the development of each living lab. Our findings demonstrate how the relational nature of the living lab innovation platform emerges, showing growth is founded on the co-ordination of inter-organizational relationships between key actor groups as follows: university, industry and users. The platforms' evolution depends not on the initiating organization, but rather on joint activities, such as planning and problemsolving. Furthermore, the research characterizes a new form of coordination of innovation platform, a peer-to-peer approach, which supports the generation of collective goals and development of critical joint activities.

In the next section, we introduce the innovation platform perspective, focusing on management and governance modes. This is followed by an explanation of the research approach and a description of the cases and findings. Finally, we present the theoretical and managerial implications of our findings and directions for future research.

\section{The innovation platform perspective}

The platform concept has attracted the attention of several areas of innovation research. Pekkarinen and Ulkuniemi (2008) conceptualize the platform approach as a systematic way to develop and deliver customized solutions efficiently by reconfiguring different modules. Platform thinking was initially seen as a way to ensure that internal structures did not become overly complex, as well as offering products and services that could be easily modified (Sawhney, 1998). Innovation platforms can also be applied to inter-organizational networks, with the concept of platform-based ecosystems representing a place, whether physical or virtual, to build and orchestrate interactions among innovator groups (Isckia and Lescop, 2015). The main aim of these platforms is to stimulate a virtuous circle of innovation through the combined contributions of platform owners and ecosystem members (Isckia and Lescop, 2015).
Open innovation platforms are understood to be virtual environments that allow the transfer of innovation-related knowledge (Hallerstede, 2013) that can match innovation supply and demand (Holzmann et al., 2014). Multi-sided open innovation platforms are established in a manner, which provides value to different organizations with heterogeneous interests (Loux et al., 2020). This serves as an approach to systematically attract, facilitate and orchestrate innovation with external actors (Patrucco, 2011). The goal is to develop solutions to the platform owners' problems and needs while also delivering value to other contributors (Ojasalo and Kauppinen, 2016). This requires the coordination of relationships between independent actors that can co-create, co-deliver and capture value in open platform environments (Ferraris et al., 2020). Within living lab platforms, the management approach taken by driving actors is considered to influence the novelty of innovation (Leminen et al., 2016). For value to be realized, we must consider the management and governance structures, which are crucial to the development of innovation platforms (Boudreau and Hagiu, 2009).

\subsection{Platform management and governance}

Traditionally, platform owners manage the partners hosted on platforms (coordination process) and maintain the control and cohesion of platform members (governance process) (Isckia and Lescop, 2015). Two main orientations adopted to manage such relationships are hierarchical and relational. By adopting a hierarchical governance approach, relationships are managed in a mechanistic mode, where one actor assumes the leading role in establishing the rules of interactions between parties (Colombelli et al., 2019). Adopting this top down perspective, the lead firm develops architectures to support new offering systems and coordinates network actors (Eloranta and Turunen, 2016). Lead firms, as platform owners, orchestrate their inter-organizational networks and purposefully influence and manage the development of the platform value network (Laczko et al., 2019). Moreover, platform owners can increase the depth of a platform to creating new functionalities (exploitation), and expand the breadth of a platform to search for new sources of value and creating new communities (exploration) (Evans and Schmalensee, 2007).

In contrast, from a bottom up perspective, platforms can be co-created with the involvement of users (Eloranta and Turunen, 2016; Perks et al., 2017). This focuses on the networking capabilities of actors, which enable them to influence networks to achieve collective goals (Mitrega et al., 2017). This aligns with a perspective that interdependent actors in the relationship influence each other on the basis of the resources possessed and activities performed (Ford et al., 2008). Nyström et al. (2014) suggest that greater openness in living labs increases the complexity of orchestration. Within this context, relational governance may be considered more appropriate than formal management approaches, however, its practical application in platform settings must be further explored (Yu et al., 2006). As Leminen et al. (2016) highlight, more attention needs to be paid to the nature of relationships between actors in living labs. 


\subsubsection{Mechanisms of relational governance: coordination of inter-} organizational relationships

Generally, governance refers to organizational or structural arrangements designed to determine and influence the behavior of network members (Das and Teng, 1998). Through governance mechanisms, firms can influence interorganizational exchange and reduce opportunistic behaviors (Jap and Ganesan, 2000). Typically, contractual (formal) governance is used simultaneously with relational governance. The latter can be considered the less formal or prescriptive approach, founded in implicit understandings, shared cooperative norms and informal routines that are mutually defined and adjusted by the parties (Gibbons and Henderson, 2012; Poppo et al., 2008).

Relational norms can be considered to constitute the normative element of relational governance while collaborative activities represent the behavioral aspect (Poppo et al., 2008; Claro et al., 2003). Combining these two concepts, Zhou et al. (2015) define relational governance as comprising both relational norms and collaborative activities. Relational norms are founded on trust, commitment and cooperation (Ivens, 2002). Collaborative activities can include routines, programs and tactics jointly carried out to achieve organizational goals (Heide, 1994). Collaborative activities involve coordination and cooperation, relying on joint planning and problem-solving (Claro et al., 2003). Joint planning helps establish mutual expectations and specifies cooperative efforts at the start of a relationship. Following on, joint problemsolving involves the resolution of disagreements with a partner, through the efforts of both parties (Claro et al., 2003). This process facilitates relationship maintenance and growth, generating mutually satisfactory solutions (Zhou et al., 2015).

The two mechanisms of relational governance (relational norms and joints actions) are crucial to maintain business relationships based on common goals. From a network perspective the mutual alignment of goals involves the recognition of the self-interest and collective interest, which coexist in relationships (Medlin et al., 2002). As stated by the actors, resources and activities (ARA) model, actors share resources and develop activities through interconnected relationships (Håkansson et al., 2009). Joint actions are, thus associated to relational activities (Håkansson et al., 2009) that involve processes of combining, developing, exchanging or creating resources through other resources (Aarikka-Stenroos and Jaakkola, 2012). Individual activities are embedded in the activity structures of firms that, in turn, are embedded in wider activity patterns (Håkansson and Snehota, 1995).

An important, yet little understood concept relevant to relational governance is the notion of atmosphere. The previously described joint actions both simultaneously influence and are influenced by the atmosphere encompassing the relationships. From this perspective, the atmosphere can be loosely equated with the rules governing the relationship and the emotional setting within which interactions occur (Hallén and Sandström, 1991). The relational atmosphere is viewed, as both a product of the relationship and a factor contributing to future relationship development (Håkansson et al., 2009; Hallén and Sandström, 1991). It should be noted that perceptions of the atmosphere are likely to differ between partners, and therefore, no static representation of atmosphere is possible (Sutton-Brady, 2001). There have, however, been attempts at defining dimensions of relational atmosphere, for instance - cooperation conflict, power/dependence, trust/opportunism, closeness/distance and expectations (Sutton-Brady, 2001). Given its dynamism, the relational atmosphere can, therefore, represent a central concept in understanding how governance approaches shape the growth of innovation platforms.

\section{Research methodology}

The study combines elements of researcher auto-ethnography (Ellis et al., 2011) with qualitative interviews and document analysis, to develop an understanding of governance approaches in innovation platform growth. This approach enabled an in-depth, longitudinal view of the phenomenon, drawing upon multiple, cross-disciplinary perspectives from researchers with varying levels of involvement with the cases (Table 1). The combination of research perspectives enabled the research team to scrutinize both the theoretical and practical aspects of living labs and relational governance, comparing both insider and outsider views.

Table 1 Researchers activities and roles in the conceptualization, production and investigation of the two case studies

\begin{tabular}{lll}
\hline Researchers & Relationship to cases & Research role \\
\hline $\begin{array}{l}\text { R1 } \\
\begin{array}{l}\text { Perspective: sustainable design } \\
\text { and construction }\end{array}\end{array}$ & $\begin{array}{l}\text { R1 was active during the development of both cases } \\
\text { Proposed the initial concept of both SLL and CLL and } \\
\text { attracted funding for their development. Facilitated the } \\
\text { creation of a consortium of industry partners in both cases }\end{array}$ & $\begin{array}{l}\text { Developed auto-ethnography based on reflections of } \\
\text { involvement in both cases }\end{array}$ \\
$\begin{array}{ll}\text { R2 } \\
\begin{array}{l}\text { Perspective: sustainable design } \\
\text { and construction }\end{array}\end{array}$ & $\begin{array}{l}\text { R2 was active during the development of the CLL and } \\
\text { visited the SLL once in operation } \\
\text { in its construction }\end{array}$ & $\begin{array}{l}\text { Developed auto-ethnography based on reflections of } \\
\text { involvement in CLL }\end{array}$ \\
& $\begin{array}{l}\text { Interviewed other participants in the SLL case } \\
\text { Compiled notes of workshops and meetings relating to the } \\
\text { development of both cases } \\
\text { Co-developed timeline of activities relating to the development } \\
\text { of both cases }\end{array}$ \\
R3 and R4 & Both R3 and R4 are independent from the cases and had \\
$\begin{array}{l}\text { Perspective: business-to- } \\
\text { business marketing }\end{array}$ & no involvement in their development & $\begin{array}{l}\text { Interviewed R1 and R2 } \\
\text { Interviewed other participants in the SLL case } \\
\text { Co-developed timeline of activities relating to the development } \\
\text { of both cases }\end{array}$ \\
\hline
\end{tabular}




\subsection{Case study design}

The research applies a comparative multi-case study design based on two similar living lab projects. Case studies were appropriate for our research focus as they allow for a richness of data to be considered within a complex changing context (Yin, 2009). Through this approach, we seek to explore commonalities and differences in the chosen settings, as a way to derive an understanding of governance dynamics over time within the respective living labs. Furthermore, purposive sampling was used to identify two embedded cases with overlapping participants, so as to partly reduce contextual diversity and enhance our ability to develop a detailed understanding of processes (Harrison and Easton, 2004). Leminen et al. (2016) specifically call for qualitative approaches to exploring innovation in living labs across countries and time.

The cases were developed based on an auto-ethnographic approach, complemented by participant interviews and secondary data analysis. Auto-ethnography is a research approach that describes and systematically analyzes personal experience to understand complex social phenomena (Ellis et al., 2011). This aligns with the broader category of ethnographic research designs, considered valuable in business and innovation research (Hoholm and Araujo, 2011), as they diminish the "relevance gap" and allow for "thicker descriptions of organizational reality and richer representations of companies' lived experience" (Visconti, 2010, p. 25). Our auto-ethnographic approach stems from the active involvement of two of the research team in the case study phenomenon, combined with two additional non-participant researchers.

Data was primarily collected as part of a broader participatory research project involving the design and management of living labs oriented toward sustainable construction. Researchers 1 and 2 were intimately involved at various stages of living lab design and development in both cases, as representatives of the university (Table 1). Through this involvement, self-narratives were developed based on reflections of personal experiences, proceedings from steering group meetings and notes taken throughout the design, development and implementation of the living labs. Regarding the first case site, R1 and a group of architects, masters' students and stakeholders participated in weekly brainstorming meetings over three years (2012-2015). These meetings covered a range of topics from defining the initial project scope, to discussing construction and management. In relation to the second case, R1 and R2 participated in more than 20 stakeholder meetings and weekly field work observation over four years (2017-2020). Meetings lasted between $30 \mathrm{~min}$ and 2 $\mathrm{h}$ and involved building design, project planning, partner goal discussions and resourcing activities.

To include other perspectives of relational governance, 14 semi-structured interviews were also conducted with key informants involved in the cases (six from the Sustainable Living Lab (SLL) case and eight from the Circular Living Lab (CLL) case; the two cases are defined in Section 3.3 below). The key informants were, in addition to the living lab creators, researchers from both the participating universities and facility managers. The interviews lasted between $40 \mathrm{~min}$ and $1 \mathrm{~h}$ and were held locally or through online video-calls. Questions focused upon the conceptualization of living labs, main stages of living lab development, key activities and resources shared within living labs and challenges arising in the development and operation of living labs. Furthermore, a relational focus was taken to explore participant thoughts on the role of different actors, examples of interactions between actors and perceptions of the coordination of inter-organizational relationships. Responses were recorded and transcribed for analysis. Secondary data was also collected from multiple sources to triangulate the insights gained auto-ethnographic narratives and participant interviews. This included internal documents such a minutes of meetings, external publications and media coverage across the study timeframe.

\subsection{Analysis approach}

In line with the case study design, we adopted an iterative analytical approach (Ployhart and Bartunek, 2019). A multi-stage coding process was used to inductively develop theoretical descriptions of the contexts of the phenomena investigated (Gioia et al., 2013). We started to build our theory by categorizing the data based on the governance challenges the key informants were talking about (first-order concepts) (Table 2).

Broader themes were then created based on our interpretations of the experiences expressed by respondents. The second-order themes were platform stagnation/growth, activities and resource contributions, failure of top down perspective/limitations of a bottom up perspective, misalignment of goals, generation of collective goal. We also conducted a literature review to inform our organization of thematic categories, particularly around the concepts of innovation platforms and relational governance. We articulated these second-order themes into aggregate dimensions as follows: Platform evolution, relational platform, drivers of relational governance, joint activities/joint goals.

The development processes of the living labs were organized in accordance with the main stages of their evolution, as identified during the analysis. These stages related to importance changes in dynamics within the platforms' evolution: from platform idea to conceptualization, from platform conceptualization to launch, from platform launch to growth. To further examine the relational governance perspective as described in the Industrial Network literature, in each stage we investigated the main actors providing resources, their goals and the main activities developed. Through this approach, we are able to take into account multiple actor perspectives as a way to understand evolving network structures and processes, focusing in particular on joint activities.

\subsection{Case contexts}

The cases selected shared several similarities, which offer a good basis for comparison. In both cases, the initial idea for establishing a living lab started from the university. Both platforms can be considered to have reached some degree of maturity considering the number of projects and activities taking place within them. Moreover, both living labs focus on studying innovation in the context of sustainable construction, broadly defined as minimizing the consumption of resources and maximizing the re-utilization of resources (Cruza et al., 2019).

\subsubsection{Sustainable Living Lab}

The SLL is a multi-story, modular building based in Sweden, composed of 44 steel frame modules, hosting 29 student 
Table 2 The iterative analytical approach

\begin{tabular}{|c|c|c|}
\hline First-order concept & Second-order concept & Aggregate dimensions \\
\hline $\begin{array}{l}\text { The number of projects improved during the time } \\
\text { The activities of the living lab have been changed during the time } \\
\text { There was a period when the projects stopped }\end{array}$ & $\begin{array}{l}\text { Platform stagnation } \\
\text { Platform growth }\end{array}$ & Platform evolution \\
\hline $\begin{array}{l}\text { Each partner developed specific projects and activities } \\
\text { The living lab involved different stakeholders } \\
\text { Each stakeholder is very important providing specific knowledge } \\
\text { The results are not so good as the management decisions are weak } \\
\text { Now the project group has the responsibility for the project }\end{array}$ & $\begin{array}{l}\text { Activities } \\
\text { Resource contributions }\end{array}$ & Relational platform \\
\hline $\begin{array}{l}\text { The university at the beginning depicted the rules, then the lead role was undertaken by } \\
\text { [actor] } \\
\text { At the beginning the point of view of the users was not considered } \\
\text { This approach reduced the commitment of the partners } \\
\text { This orientation generated confusion }\end{array}$ & $\begin{array}{l}\text { Failure of top down } \\
\text { perspective } \\
\text { Limitations of a bottom up } \\
\text { perspective } \\
\text { Complexity of business } \\
\text { relationships }\end{array}$ & $\begin{array}{l}\text { Drivers of relational } \\
\text { governance approach }\end{array}$ \\
\hline $\begin{array}{l}\text { The aim of National HC was to improve the commercial nature of living lab for its purposes } \\
\text { The university wanted to develop applied research at the living lab but it had no possibility } \\
\text { Students at the beginning considered the living lab for its sustainable nature but then they } \\
\text { became interested in comfort dimensions } \\
\text { The industry firms focused only on their own goals } \\
\text { Nowadays our living lab is a community }\end{array}$ & $\begin{array}{l}\text { Misalignment of goals } \\
\text { Generation of a collective } \\
\text { goal }\end{array}$ & Joint goal development \\
\hline
\end{tabular}

apartments. The facility opened in 2015 as a collaborative project between a Swedish university and a National Housing Cooperative (HC), which sought to create a space that would help researchers explore the home-human relationship: how people use their dwellings, and how the dwellings can improve peoples' lives. It is equipped with more than 2,000 sensors that test thermal performance (internal temperature changes relative to external climate), energy and water consumption and air quality. It features interchangeable façade panels that allow industry and researchers to test new building products and materials in an operationally functional facility, thereby creating multiple potential formats for future use of the space.

\subsubsection{The Circular Living Lab}

The CLL is a research facility developed with the intention of fostering circular economy principles in building construction. It is situated in new Australian housing development and is fully owned by a local university. The project leaders include academics who were active participators in the SLL case, who sought to further develop the living lab methodology based on their prior experiences. The living lab is an example of a reusable, movable and adaptable construction, designed with the application of circular economy principles (reduce, reuse and recycle - the $3 \mathrm{R}$ 's concept) to diminish the waste created during the construction, utilization and demolition phase of buildings. It is composed of eight steel modules, salvaged from a previous project, and is entirely disassemble and planned for relocation in three years. It is equipped with sensors to test the thermal performance, electricity, water consumption and air quality. The living lab is intended to foster innovation networks by hosting industry partners and researchers working in the field of building sustainability, and startup designed products which can be tested in the facility.

\section{Findings}

The analysis of the two cases enabled us to develop a deep understanding of the evolution of the innovation platform up until maturity. We observed innovation processes taking place through inter-organizational relationships, which enable resource sharing, primarily knowledge, between key actors (university, business partners, users). Moreover, platform evolution from one stage to another was founded on the coordination of inter-organizational relationships, and thus a relational governance approach. Findings are presented in line with the main development stages identified in the analysis.

\subsection{Case one: sustainable living lab}

4.1.1 From platform idea to concept (2012-2013)

The original idea for the SLL was born via a fortuitous postconference meeting in 2012 between a university academic and a manager from an adjacent Science Park (SP) in which they shared their mutual interest in European living labs. Following this encounter, the SP engaged one of their major business partners, the National HC, which expressed interest in developing a modular student housing design. Over the course of several interactions, the $\mathrm{HC}$ and University began to identify areas of mutual interest between their available expertise and resources that could be put toward a new living lab to be located at the SP.

Each actor provided resources ( $\mathrm{R}$ ) and developed activities (A) to collaboratively ideate the platform concept, with each pursuing the own goals. For example, the University provided technical knowledge $(\mathrm{R})$ and defined the living lab approach (A) aimed at creating knowledge on sustainability topics. The HC provided access to its network of industry partners (R) and collaborated with the SP in creating a wider network of accessory providers (A). HC aimed at promoting its brand image as an innovator. The SP provided its technology transfer 
expertise (R) and facilitated the activation of relationship between the University and the HC (A). Its goal was technical innovation (Appendix 1).

The university planned regular meetings (twice a week) with $\mathrm{HC}$ and the SP to discuss their ideal living lab format. Through these meetings, the actors developed a list of potential ideas, and defined a collective goal: to develop a space to promote innovations toward sustainable living (Appendix 2). As the general direction of the living lab was formally agreed upon, it was aligned with a broader university research program examining future homes.

\subsubsection{From platform concept to launch (2014-2015)}

Following the preliminary agreement between the University, $\mathrm{HC}$ and SP, the main partners began the process of developing the Living Lab. As a starting point, the University provided expertise on the living lab methodology and how to drive research activity within the space, as well as access to Swedish and European Union research funding (R). The SP shared its expertise to support the involvement of business partners (A). HC brought financial resources and the involvement of additional business partners (R), coordinating their interactions with the University (A). HC also provided access to the rest of the value chain needed for developing the platform through their existing business relationships and the expertise to manage the facility. Industry partners provided accessories (R) for use in the facility and monitored their installation (A) (Appendix 1).

At this time, the university was focused on driving research interest within the space while the SP aimed at expanding its network through the increase in activity on their site. Similarly, the $\mathrm{HC}$ aimed to both create and consolidate relationships with industry stakeholders and establish an industry research fund while most industry partners were focused on testing their products and integrating the living lab into their innovation processes. HC initiated several meetings and workshops with university and industry partners, to establish a suitable platform business model (Appendix 2). Platform ownership was determined to be a joint venture between industry partners but led by $\mathrm{HC}$.

A new HC manager and University Academic responsible for the initial conceptualization collaborated to present the living lab proposal to industry partners. Public interest was also attracted through promotion at national meetings, using existing HC connections. The industry engagement process was used to collect contributions in the form of funding, inkind resources and knowledge to inform living lab design and activities. A consortium model was established whereby companies paid an annual fee of approximately $€ 4,000$ to become official members. The coordination of the consortium was the responsibility mainly of the HC, with support from the University. HC also planned to offset the greater proportion of the cost of the building through rental income generated from accommodation provided to users renting rooms in the living lab. During this stage, the University was limited in sharing its knowledge about living lab planning (R) and carried out only few workshops aimed at developing the platform around the idea of sustainable living (A). HC aimed to supervise the living lab and managed partners during the construction stages (A), as well as bringing in financial resources and project management capabilities ( $R)$.

\subsubsection{From platform launch to stagnation (2016-2017)}

As soon as the living lab was built, it experienced some initial success with a full occupancy rate for rooms, due in part to the convenient location and shortage of student accommodation. Despite this success, the number of research projects taking place in the living lab was limited and the facility struggled for recognition as a university asset. Industry partners, such as architects, shared technical knowledge while other providers brought in whitegoods, technical expertise, energy and interior decorating capabilities (R). Industry some partners tested their new products with students, providing usable products $(\mathrm{R})$ to undertake household tasks (A) (Appendix 1).

Activities within the facility were dominated by more applied industry research and development, as well as commercially focused events. An example of this is the company hiring the space for product demonstrations rather than testing and prototyping. This conflicted with the original ideas of using the living lab for collaborative research with academics and for innovative sustainability projects. Some researchers have found that industry partnerships were limited to mostly in-kind contributions of material or products, with a limited corporate appetite for riskier radical projects. Therefore, during this period, the commercial goal of $\mathrm{HC}$ and industry partners prevailed over research goals. Few research projects were carried out in this period and the facility was mainly used as a marketing exercise for industry partners (Appendix 2). This was exemplified by one project idea that involved testing new windows and other façade elements, which one respondent suggested was canceled because of the perceived risk of adding new elements, which could disrupt the normal operations of the facility.

\subsubsection{Platform growth (2018-2020)}

After this period of stagnation, the Living Lab began to experience a large increase in the number of projects carried out. After some of the facility managers were substituted with new personals appointed by the University, which meanwhile provided research capacity and capability ( $R$ ) to develop a portfolio of research projects (A). The SP acted as an intermediary to broker new relationships across the city (R), using collaborative activities within the living lab to strengthen their own network. The HC focused on the continuing development of innovation (A) projects and provided management capability $(\mathrm{R})$ to support. The industry partners brought in products, technology and financial support $(\mathrm{R})$ for testing their solutions prior to market launch (A). This was supported by users who tested products (A) and shared their experiences (R), aligning with the common living lab goal of living more sustainably and contribute to knowledge creation (Appendix 1).

The realignment of goals was set in motion when facility managers were substituted and workshops were held focusing on the purpose of the living lab (Appendix 2). This was also encouraged by new industry partners introduced by the University and HC. Outcomes of this joint planning were new innovation projects involving several actors. This interaction supported the realignment of goals, leading to a re-birth of the platform and an increase in collaborative activity between 
users, researchers and industry. This re-birth was referred to by University researchers as "a space where actors are active in cocreation, innovation and experimentation. The Living Lab, at the moment, is very active, with more than 20 big projects".

This represented a shift in priorities within the living lab, as indicated by one of the researchers involved "during the years there have been different markers of living lab success. At the beginning, the number of partners, then the fact that the living lab was running. Later, the SLL measured its success only through the financial dimensions. Now, the growth concerns the income generated at the SLL and the number of projects per year". The additional traction resulted in the development of applied research projects through a project group made up by the university, HC, technology company, architectural firm and builder, as well as several equipment suppliers.

\subsection{Case two: a circular living lab}

\subsubsection{From platform idea to concept (2017-2018)}

The idea for the CLL stemmed from a team of three Australian University researchers working in the area of the circular economy. Based on some of the team's previous involvement in the SLL, the researchers decided on several new approaches to achieve sustainability innovation outcomes through a living lab platform. As one researcher suggested, the original motivation was to improve waste reduction in a challenging context: "In Australia, the construction industry is responsible for about $30 \%$ or 20.4 million tons of annual waste. Although it's a significant and largely ignored issue, this is also an opportunity". At this stage, the University, through its project team, provided technical knowledge $(\mathrm{R})$ to develop the initial conceptualization of the CLL (A).

Alongside the University contributions, a state government agency agreed to provide financial support and a lease for the required land $(\mathrm{R})$, as well as promoting the project to a network of potential partners (A). The focus on circular economy innovation was a key determinant in the founders' strategic choices of selecting the industry partners. These partners, identified as "knowledge contributors" (R), brought in their competencies relating to circular economy products to support the development of the concept (A) (Appendix 1).

On the basis of their experience with the SLL, goal alignment was sought through several strategizing meetings that allowed for discussion around the purpose, responsibilities and expectations (Appendix 2). This led to three complementary aims for the key stakeholders as follows: the university was aiming to develop a modern research facility based on an overarching theme; industry partners were interesting in commercializing new products; and the state government was motivated to support new construction practices and improve its image.

The outcome of this collective action was the establishment of long-term plans for the project. The university and its researchers were to assume ownership and be responsible for the coordination of activities. All actors agreed upon the conceptualization, including features in line with a new generation of the living lab. In an effort to avoid the initial stagnant period of the SLL, a guiding principle was adopted for the CLL that the space should maintain a research focus that achieved academic, commercial and social outcomes. In addition, the living lab would place emphasis on becoming a collaborative space to work on practical circular economy projects.

\subsubsection{From platform concept to launch (2019-early 2020)}

A formal partnership was signed with a state government agency that agreed to provide a block of land $(R)$ in a new housing development for a minimum period of two years and AUD $\$ 100,000$ funding toward construction. The government agency needed a functioning building on their development site to host meetings and to use as a sale office for the upcoming construction site (A). Companies were recruited to become involved in the project based on their interest in circular construction practices. These industry partners provided their products, labor and expertise (R), which served to test their innovative solutions in practice (A). The university team provided management capability $(\mathrm{R})$ and focused on attracting new partnerships (A) (Appendix 1).

The University also sought to align partners toward the committed goal and coordinate research projects. The state government agency intended to use the facility as an office and showcase space for events, bringing in an established network of partners from other projects. The industry partners aimed to use their involvement for promotional purposes and increase exposure for their circular economy products and practices. In addition, smaller companies became tenants (users), also contributing financial support, knowledge $(\mathrm{R})$ and links to new industry partners (A). These users were interested in accessing the network of interested firms, and in the use of the platform both as an office and for testing new products. To build upon previous living lab management experiences, all actors were involved in regular meetings to align the goals and the priorities (Appendix 2).

A decision was made to run the living lab platform primarily as a research asset, with its main source of income being research funds from government or industry project grants rather than rental income. As such, more strategic uses could be pursued, such as providing free space to start-ups, which would better align with the innovation aims of the living lab. This focus also determined business partner and projects selection. Through this strategic research focus, the CLL was designed to be an active and vibrant space for collaboration. A Gantt chart was implemented to schedule the different steps of living lab development, coordinating the tasks and inputs for each actor. In line with circular economy principles, the foundation steel frames were salvaged and sound absorbent ceiling panels were made from recycled plastic bottles. As stated by one of the university researchers: "The carpet is from a near-new office space that was being renovated and it was due to be thrown away before we repurposed it. It's secured with a double-sided contact pad, rather than glue, meaning it can potentially even be reused again in the future".

\subsubsection{The platform growth (early 2020-late 2020)}

In the early months of 2020, the CLL grew both in the number of users and innovation projects initiated. The university with its team provided the applied research skills $(\mathrm{R})$ to coordinate projects with the partners, which started to bring in new products and services $(\mathrm{R})$ for testing their innovative solutions (A). This is exemplified by a manufacturer (an initial industry partner), which planned to test the quality of their new doubleglazed windows by monitoring the electricity expenditure in the 
building before and after their installation. Another manufacturer became a new industry partner by donating automatic blinds and used energy consumption data to measure performance. New partnerships were attracted with a mining company interested in building a worker village using the CLL as a blueprint for sustainable construction (Appendix 2).

Additionally, the CLL was used to support the local community (A) by providing a space for precinct meetings and local events. Community events were held every 4-6 weeks while the space was also used for conferences to raise community members' awareness of sustainable construction and circular economy in the building sector. The need for the living lab to maintain openness to new actors was exemplified by one start-up manager's perspective: “a crucial aspect is that the circular living lab is open to the public during its testing phase, ensuring people can learn about circular economy and experience first-hand the future possibilities of modular living". Meanwhile, the government agency provided additional financial resources $(\mathrm{R})$ to promote activities (A), generating media coverage of the living lab. The user firms initiated applied innovation projects (R), collaborating with the university researchers (A) (Appendix 1). In its operation stage, the living lab provides a meeting and co-working place for researchers, society and industry, with the facility being used to host regular showcases on building design and construction.

\section{Discussion}

\subsection{The relational nature of living lab platforms}

The cases offer examples of how living labs function as innovation platforms, in stimulating a virtuous circle of innovation between multiple diverse parties (Isckia and Lescop, 2015). In both the SLL and CLL, stakeholders including university researchers, industry partners and users, maintained individual motivations for participation while recognizing the benefits of networking with other members to achieve innovation outcomes and identify previously unconsidered collaboration opportunities. The living lab is, therefore, not generated in a vacuum but depends on a network of actors that combine resources and develop a constellation of activities oriented to innovation. As emphasized in both cases, the platform includes not only the physical space but also the relational space to support the ideation, development and commercialization of innovation. For the living lab to serve as a functioning innovation platform, consideration should be given to the nature of the relational atmosphere, which develops and evolves through inter-organizational relationships (SuttonBrady, 2001). In both cases, the university undertook the role of the activator but it had to develop relationships with industry partners and public actors to advance conceptualization and grow the platform. As previously suggested, the development of the platform involves new functionalities and/or new sources of value, as well as the creation of new communities (Evans and Schmalensee, 2007).

The growth of the platform involves not only increasing revenue or the number of active projects but also the development of relationships between members of the living lab community. In both cases, the growth stage has been reached through encouraging increased user and industry involvement in research activities and greater interaction between members. The importance of user relationships is, therefore, paramount to the platform, as both cases demonstrated challenges when users were not active in early development stages, as well as the positive impact once aims were aligned and interaction within the community increased (Hagy et al., 2017). The growth of the living lab is, therefore, founded on the cooperation and commitment of key actors from platform ideation stages to support its evolution. These inter-organizational relationships require ongoing coordination through relational governance across the life of the platform (Colombelli et al., 2019).

\subsection{The governance of innovation platforms}

5.2.1 Relational atmosphere and the nexus of goals

As depicted in the cases, governance requires the coordination of inter-organizational relationships and joint activities founded on a process of interaction. This, in turn, involves the coordination of heterogeneous goals, recognizing that each actor has their own goals that could be similar or different, from those of other actors. Goal heterogeneity is understood to generate both complexity and value (Corsaro et al., 2012) and this logic can be extended to living lab settings. As stated by Nyström et al. (2014), the simultaneous pursuit of disparate goals in living labs necessitates goal ambidexterity among actors.

In both living labs studies, the university actor performed the role of platform activator, which we understand to encompass the original ideation and various activities to drive platform development across all stages. Given the specific focus on the research actor and including stages prior to the opening of the living lab, this description does not neatly align with the existing definition of actor roles (Nyström et al., 2014). Platform evolution required consideration of all actor goals and collective goals determined through a process of interaction. The SLL in particular demonstrated issues stemming from a failure to maintain a collective goal, leading to stagnation during a period where HC took more control. Platform growth was eventually enabled through the identification of a new collective goal (re-birth of the platform), generated through several meetings to understand and re-align the goals of key actors. Similarly, in the CLL, the collective goal (development of innovative research projects) at the growth stage was founded on the goals of each key actor as follows: conducting research (university), activating facility (government), product testing (industry partners), improve networking (users).

Figure 1 illustrates how a collective goal can be perceived to sit within the nexus between university (research), government agencies and business partners (industry) and users. In this example, business partners can include various non-academic stakeholders, both government and private. The collective goal (dot) is determined through interaction processes that characterize each stage of the platform's evolution and its orientation can change through each stage. The inner area (dashed line) indicates the acceptable range (relational atmosphere) within which the collective goal can move while still delivering value to all actors involved, maintaining their contributions and commitment. This captures the dynamism of collective goals throughout living lab development and operational phases, suggesting there is a degree of acceptable 
Figure 1 The dynamism of collective goals

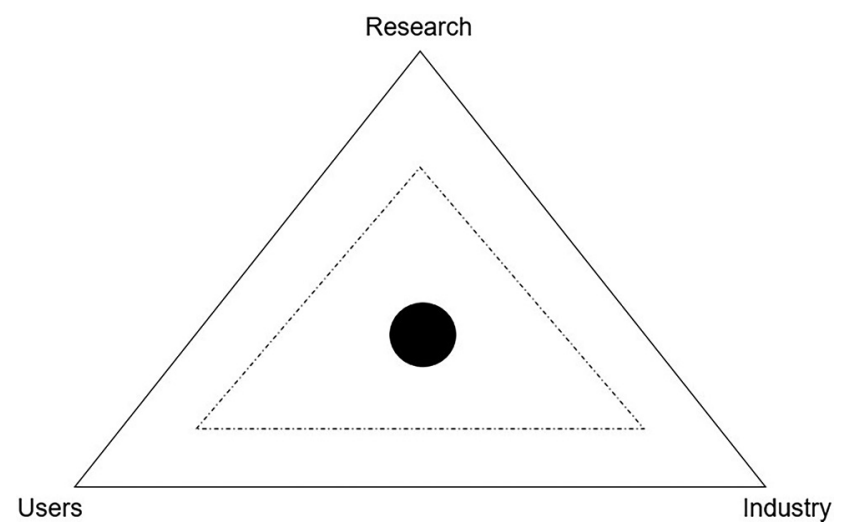

flexibility, which can be negotiated through actor interactions (Sutton-Brady, 2001).

\subsubsection{Foint activities in inter-organizational relationships}

A further insight from the case findings relates to the coordination activities identified during the various stages of living lab development. To remain within the inner nexus, ongoing relational governance, founded on joint action and joint planning, is required. Previous research has presented typologies of living labs based on the characteristics of actors responsible for different activities in the living lab network (Leminen et al., 2016). From this perspective, managerial and intra-organizational dynamics often involve top down approaches and autocratic leadership styles (Venselaar et al., 2015). Lead firms traditionally managing in a top down approach can improve the alignment of goals through careful and deliberate coordination of resource contributions and activities. This represented in the SLL case when the lead firm (HC) defined the main goal of the living lab, but this approach neither did allow the exploitation of the full innovation potential of the platform nor did it maintain engagement and contributions from all members.

In contrast, the new approach adopted by SLL and CLL highlights that a traditional lead firm is not sufficient to support the platform evolution and maintain a focus on sustainability research and innovation. While platforms are often aligned with either top down and/or bottom up approaches, a blend of the two approaches bodes well for relational governance (Gupta et al., 2007). Adopting a relational perspective, supports interaction which enables a continuous processes adaptation and collective learning among actors (Håkansson et al., 2009). The growth stages of both living labs were founded on peer-topeer business relationships that go beyond the top down and bottom up coordination. Based on the insights from the cases, once the living labs are operational, a shift from vertical to horizontal coordination can occur, supported by higher commitment in the generation of collective goals.

Joint activities within living labs encourage shifts from formal contractual relationships to deeper co-creation, which supports the innovation platform evolution. The cases show the role of joint planning and problem-solving at different stages of platform evolution. Joint actions can relate to the proactive joint setting of goals that make the future of a relationship foreseeable (Claro and Claro, 2010). A critical joint activity identified across both cases was the generation of collective goal. We identify key joint activities for each stage of platform evolution, in particular those initiated by the university as platform activator.

The first stage (from platform idea to conceptualization) involves the co-creation of a vision, mission and values between the key actors of the living lab. Subsequent key activity is the co-creation of a platform model to satisfy the value proposition. At the second stage (from platform conceptualization to launch) the key joint activities identified are the co-creation of platform configuration and development of criteria to select projects, planning of activities, organizing of processes. The key activities for the platform activator are the identification of industry partners to create the platform and the co-ordination of activities within the living lab. At the third stage (platform growth) the key joint activities relate the co-creation of research and business goals for each project, coordination of contributions and tracking of project results and key performance indicators. The platform activator should be involved in the fostering of a living lab community and eliciting industry partner and user feedback. Joint action can be facilitated through business coaching activities developed by the platform activator, in each stage of platform development, to support the sharing of goals and to improve the commitment and the engagement of the actors involved.

\section{Conclusions}

\subsection{Theoretical implications}

As depicted Isckia and Lescop (2015), the main aim of the platform is to stimulate a virtuous circle of innovation. Although the platform concept has traditionally been technology and product-based, they are shifting toward a value and network-centric focus established on the joint actions of network actors rather than on the features of products (Perks et al., 2017). In this context, living labs can be considered a sociotechnical platform that organizes its stakeholders into an innovation ecosystem (Westerlund et al., 2018). We perceive a living lab as primarily a relational platform where three main participants, universities, industry partners and users, work together to foster co-creation and open innovation outcomes within a broad agenda.

While network perspectives has previously been adopted in investigating living labs (Westerlund et al., 2018; Leminen et al., 2016; Nyström et al., 2014), this paper focuses specifically on the nature of relationships and their governance over the course of living lab development. Through interorganizational relationships, the key actor groups share the tangible and intangible resources required to develop joint activities for collective and individual innovation processes. A key challenge for living lab platforms is to develop an effective way to coordinate interactions and maintain alignment between the nexus of goals of all parties (Leminen et al., 2016).

Insights from both cases show that relational governance relies on cooperation to co-ordinate relationships (Claro et al., 2003) and is crucial to support the transition from initial platform idea to growth. Formal governance considerations may refer to specific interactions, such as institutional relationships between consortium members, intellectual property and research output; however, these mechanisms are 
not sufficient to support platform growth (Gibbons and Henderson, 2012; Poppo et al., 2008). While other studies have examined top down governance approaches of living lab platforms, orchestrated by a lead firm, this paper demonstrates the bases for a relational approach. In line with the industrial network approach (Håkansson and Snehota, 1995), governance is facilitated through inter-firm relationships.

Platform growth is, thus founded on the generation of a collective goal through a process of interaction that simultaneously influences and is influenced by joint activities. Joint actions have been considered to refer to proactive and bilateral goal setting (Ivens, 2002). This process can start with the identification of needs and covers management of conflicts, organizing processes and resources (Aarikka-Stenroos and Jaakkola, 2012). As depicted in the findings, a critical joint problem-solving activity relates to maintaining commitment toward collective living lab goals, which remain within an acceptable nexus between the individual interests of key actors (university, business partners and users). This process should not only inform the first stage of platform development but also each subsequent stage and take into account the shifting relational atmosphere in which it exists (Sutton-Brady, 2001).

This paper has offered an insight into the role of platform activators, in this case University actors that bring a research agenda to the governance of living labs. It follows that platform evolution is founded not only on the key activities developed by the activator but also by joint activities developed by all actors (Leminen et al., 2016). Key joint activities include the sharing of vision, mission and values of the innovation platform, the coconfiguration of the platform, the identification of project selection criteria, as well as the sharing of the results. In particular, these key joint activities depict the relevance of collective perspective related to the determinant stages of the platform evolution.

\subsection{Managerial implications}

Innovation platforms must bring together diverse players through their common interest in innovation and deliver outcomes for all actors involved. Our findings indicate that a relational governance approach constituted by groups of actors supports research activity and outcomes.

It also suggests that the platform activator should embrace research proposals coming from industry partners while at the same time using the living lab space to involve the community in the co-creation and knowledge sharing processes. This requires the platform activator to support, a continuous process of alignment and re-alignment of actors' goals, maintaining a collective goal. In addition, a degree of equilibrium between university, business partners and users is required to manage the complexity of combining research, commercial or usage goals.

The coordination of inter-organizational relationships involves joint planning and problem-solving across each stage of platform evolution. The management of innovation outcomes from a relational governance approach draws in all stakeholders for important decisions and continues to adapt platform format as required. An aspiration of living labs should be the meaningful engagement of all actors in truly collaborative research activities, rather than only using the space for their own purposes. Living lab platform growth should not only be considered by the number of innovative projects but also the number of interactions and relationships developed between actors. Attention should be paid to the relational atmosphere, which encompassing the activities within the living lab and how that can be supported over the stages of platform development. Our evolutionary perspective highlights the dynamic nature of these relationships, suggesting that living lab development cannot be considered complete once it officially opens its doors, but must be maintained to be considered "living."

\subsection{Limitations and future research}

This paper has explored two interrelated innovation platforms with a focus on identifying the main stages of development and better understanding the relational governance role of universities. Future research has the potential to go into greater depth in other living lab cases, particularly by investigating different perspectives of individual and collective goals and how they change while developing the platform. Similarly, relational governance needs to be better understood, for instance by identifying specific mechanisms, which activating actors use to coordinate activities within living labs and the related influence on relational atmosphere within the platform.

\section{References}

Aarikka-Stenroos, L. and Jaakkola, E. (2012), "Value co-creation in knowledge intensive business services: a dyadic perspective on the joint problem solving process", Industrial Marketing Management, Vol. 41 No. 1, pp. 15-26.

Ballantyne, D. and Williams, J. (2008), "Business to business relationships: the paradox of network constraints?", Australasian Marketing Fournal, Vol. 16 No. 1, pp. 94-106.

Boudreau, K.J. and Hagiu, A. (2009), "Platform rules: regulation of an ecosystem by a private actor", in Gawer, A. (Ed.), Platforms, Markets and Innovation, Edward Elgar.

Claro, D.P., Hagelaar, G. and Omta, O. (2003), "The determinants of relational governance and performance: how to manage business relationships?", Fournal of Economic Behavior E Organization, Vol. 32 No. 8, pp. 703-716.

Claro, D.P. and Claro, O.B.O. (2010), "Collaborative buyersupplier relationships and downstream information in marketing channels", Industrial Marketing Management, Vol. 39 No. 2, pp. 221-228.

Colombelli, A., Paolucci, E. and Ughetto, E. (2019), "Hierarchical and relational governance and the life cycle of entrepreneurial ecosystems", Small Business Economics, Vol. 52 No. 2, pp. 505-521.

Corsaro, D., Cantù, C. and Tunisini, A. (2012), “Actors' heterogeneity in innovation networks", Industrial Marketing Management, Vol. 41 No. 5, pp. 780-789.

Cruza, C., Gaspar, P. and De Brito, J. (2019), “On the concept of sustainable sustainability: an application to the Portuguese construction sector", fournal of Building Engineering, Vol. 25 No. 2.

Das, T.K. and Teng, B.S. (1998), "Between trust and control: developing confidence in partner cooperation in alliances", Academy of Management Review, Vol. 23 No. 3, pp. 491-512.

Ellis, C., Adams, T.E. and Bochner, A.P. (2011), "Autoethnography: an overview", Historical Social Research, Vol. 36, No. 4, pp. 273-290. 
Eloranta, V. and Turunen, T. (2016), "Platforms in servicedriven manufacturing: leveraging complexity by connecting, sharing, and integrating", Industrial Marketing Management, Vol. 55, pp. 178-186.

Evans, D.S. and Schmalensee, R. (2007), "The industrial organization of markets with two-sided platforms", Competition Policy International, Vol. 3 No. 1, pp. 151-179.

Ferraris, A., Belyeava, Z. and Bresciani, S. (2020), "The role of universities in the smart city innovation: multi stakeholder integration and engagement perspectives", fournal of Business Research, Vol. 119, pp. 163-171.

Ford, D., Gadde, L.E., Håkansson, H., Snehota, I. and Waluszewski, A. (2008), "Analysing business interaction", The IMP fournal, Vol. 4 No. 1, pp. 82-103.

Gibbons, R. and Henderson, R. (2012), "Relational contracts and organizational capabilities", Organization Science, Vol. 23 No. 5, pp. 1350-1364.

Gioia, D.A., Corley, K.G. and Hamilton, A.L. (2013), "Seeking qualitative rigor in inductive research notes on the Gioia methodology", Organizational Research Methods, Vol. 16 No. 1, pp. 15-31.

Gupta, A.K., Tesluk, P.E. and Taylor, M.S. (2007), "Innovation at and across multiple levels of analysis", Organization Science, Vol. 18 No. 6, pp. 885-897.

Hagy, S., Morrison, G. and Elfstrand, P. (2017), "Co-creation in living labs", in Keyson, D., Guerra-Santin, O. and Lockton, D. (Eds), Living Labs: Design and Assessment of Sustainable Living, Springer, pp. 169-178.

Håkansson, H. and Snehota, I. (1995), Developing Relationships in Business Networks, Routledge, London.

Håkansson, H., Ford, D., Gadde, L.E., Snehota, I. and Waluszewski, A. (2009), Business in Networks, J Wiley, Chichester.

Hallén, L. and Sandström, M. (1991), "Relationship atmosphere in international business", in Paliwoda, S.J. (Ed.), New Perspectives on International Marketing, Routledge, London.

Hallerstede, S.H. (2013), Managing the Life Cycle of Open Innovation Platforms, Springer, Wiesbaden.

Harrison, D. and Easton, G. (2004), "Temporally embedded case comparison in industrial marketing research", in Fleetwood, S. and Ackroyd, S. (Eds), Critical Realist Applications in Organisation and Management Studies, Routledge, London.

Heide, J.B. (1994), "Interorganizational governance in marketing channels", fournal of Marketing, Vol. 58 No. 1, pp. 71-85.

Hoholm, T. and Araujo, L. (2011), "Studying innovation processes in real-time: the promises and challenges of ethnography", Industrial Marketing Management, Vol. 40 No. 6, pp. 933-939.

Holzmann, T., Sailer, K. and Katzy, B.R. (2014), "Matchmaking as multisided market for open innovation", Technology Analysis \& Strategic Management, Vol. 26 No. 6, pp. 601-615.

Isckia, T. and Lescop, D. (2015), "Strategizing in platformbased ecosystems: leveraging core processes for continuous innovation", Digiworld Economic fournal, Vol. 99 No. 3rd Q, pp. 91-111.
Ivens, B.S. (2002), "Norm-based relational behaviors: is there an underlying dimensionality structure", IMP Conference, pp. 1-14.

Jap, S.D. and Ganesan, E. (2000), “Control mechanisms and the relationship life cycle: implications for safeguarding specific investments and developing commitment”, fournal of Marketing Research, Vol. 37 No. 2, pp. 227-245.

Laczko, P., Hullova, D., Needham, A., Rossiter, A.M. and Battisti, M. (2019), "The role of a Central actor in increasing platform stickiness and stakeholder profitability: bridging the gap between value creation and value capture in the sharing economy", Industrial Marketing Management, Vol. 76, pp. 214-230.

Leminen, S., Nyström, A.G., Westerlund, M. and Kortelainen, M.J. (2016), "The effect of network structure on radical innovation in living labs", fournal of Business $\mathcal{E}$ Industrial Marketing, Vol. 31 No. 6, pp. 743-757.

Loux, P., Aubry, M., Tranc, S. and Baudoind, E. (2020), "Multi-sided platforms in B2B contexts: the role of affiliation costs and interdependencies in adoption decisions", Industrial Marketing Management, Vol. 84, pp. 212-223.

Medlin, C., Aurifeille, J.M. and Pascala, G.Q. (2002), "A collaborative interest model of relational coordination and empirical results", fournal of Business Research, Vol. 5866, pp. 1-9.

Mitrega, M., Forkmann, S., Zaefarian, G. and Henneberg, C.S. (2017), "Networking capability in supplier relationships and its impact on product innovation and firm performance", International fournal of Operations $\mathcal{E}$ Production Management, Vol. 37 No. 5, pp. 577-606.

Nambisan, S. and Sawhney, M. (2011), "Orchestration processes in network-centric innovation: evidence from the field", Academy of Management Perspectives, Vol. 25 No. 3, pp. 40-57.

Nyström, A.G., Leminen, S., Westerlund, M. and Kortelainen, M. (2014), "Actor roles and role patterns influencing innovation in living labs", Industrial Marketing Management, Vol. 43 No. 3, pp. 483-495.

Ojasalo, J. and Kauppinen, H. (2016), "Collaborative innovation with external actors: an empirical study on open innovation platforms in smart cities", Technology Innovation Management Review, Vol. 6 No. 12, pp. 49-60.

Patrucco, P.P. (2011), "Changing network structure in the organization of knowledge: the innovation platform in the evidence of the automobile system", Economics of Innovation and New Technology, Vol. 20 No. 5, pp. 477-493.

Pekkarinen, S. and Ulkuniemi, P. (2008), "Modularity in developing business services by platform approach", The International fournal of Logistics Management, Vol. 19 No. 1, pp. 84-103.

Perks, M., Kowalkowski, C., Witell, L. and Gustafsson, A. (2017), "Network orchestration for value platform development”, Industrial Marketing Management, Vol. 67, pp. 106-121.

Ployhart, R.E. and Bartunek, J.M. (2019), "Editors' comments: there is nothing so theoretical as good practice - a call for phenomenal theory", Academy of Management Review, Vol. 44 No. 3, pp. 493-497.

Poppo, L., Zheng Zhou, K. and Zenger, T.R. (2008), "Examining the conditional limits of relational governance: specialized assets, performance ambiguity, and long-standing 
ties", Fournal of Management Studies, Vol. 45 No. 7, pp. 1195-1216.

Sawhney, M.S. (1998), "Leveraged high-variety strategies: from portfolio thinking to platform thinking", fournal of the Academy of Marketing Science, Vol. 26 No. 1, pp. 54-61.

Sutton-Brady, C. (2001), "Relationship atmosphere-the final chapter”, 17th Annual IMP Conference, Oslo.

Venselaar, M., Gruis, V. and Verhoeven, F. (2015), "Implementing supply chain partnering in the construction industry: work floor experiences within a dutch housing association", fournal of Purchasing and Supply Management, Vol. 21 No. 1, pp. 1-8.

Visconti, L. (2010), "Ethnographic case study (ECS): abductive modeling of ethnography and improving the relevance in business marketing research", Industrial Marketing Management, Vol. 39 No. 1, pp. 25-39.

Wang, Y., Phillip, F. and Yang, C. (2021), "Bridging innovation and commercialization to create value: an open innovation study", Fournal of Business Research, Vol. 123, pp. 255-266.
Westerlund, M., Leminen, S. and Habib, C. (2018), "Key constructs and a definition of living labs as innovation platforms", Technology Innovation Management Review, Vol. 8 No. 12, pp. 51-62.

Yin, R.K. (2009), Case Study Research: Design and Methods, (3rd ed.), Sage Publications, Los Angeles.

Yu, C.M.J., Liao, T.J. and Lin, Z.D. (2006), "Formal governance mechanisms, relational governance mechanisms and transaction-specific investments in supplier-manufacturer relationships", Industrial Marketing Management, Vol. 35 No. 2, pp. 128-139.

Zhou, Y., Zhang, X., Zhuang, G. and Zhou, N. (2015), "Relational norms and collaborative activities: roles in reducing opportunism in marketing channels", Industrial Marketing Management, Vol. 46, pp. 147-159.

\section{Corresponding author}

Chiara Luisa Cantù can be contacted at: chiara.cantu@ unicatt.it 


\section{Appendix 1}

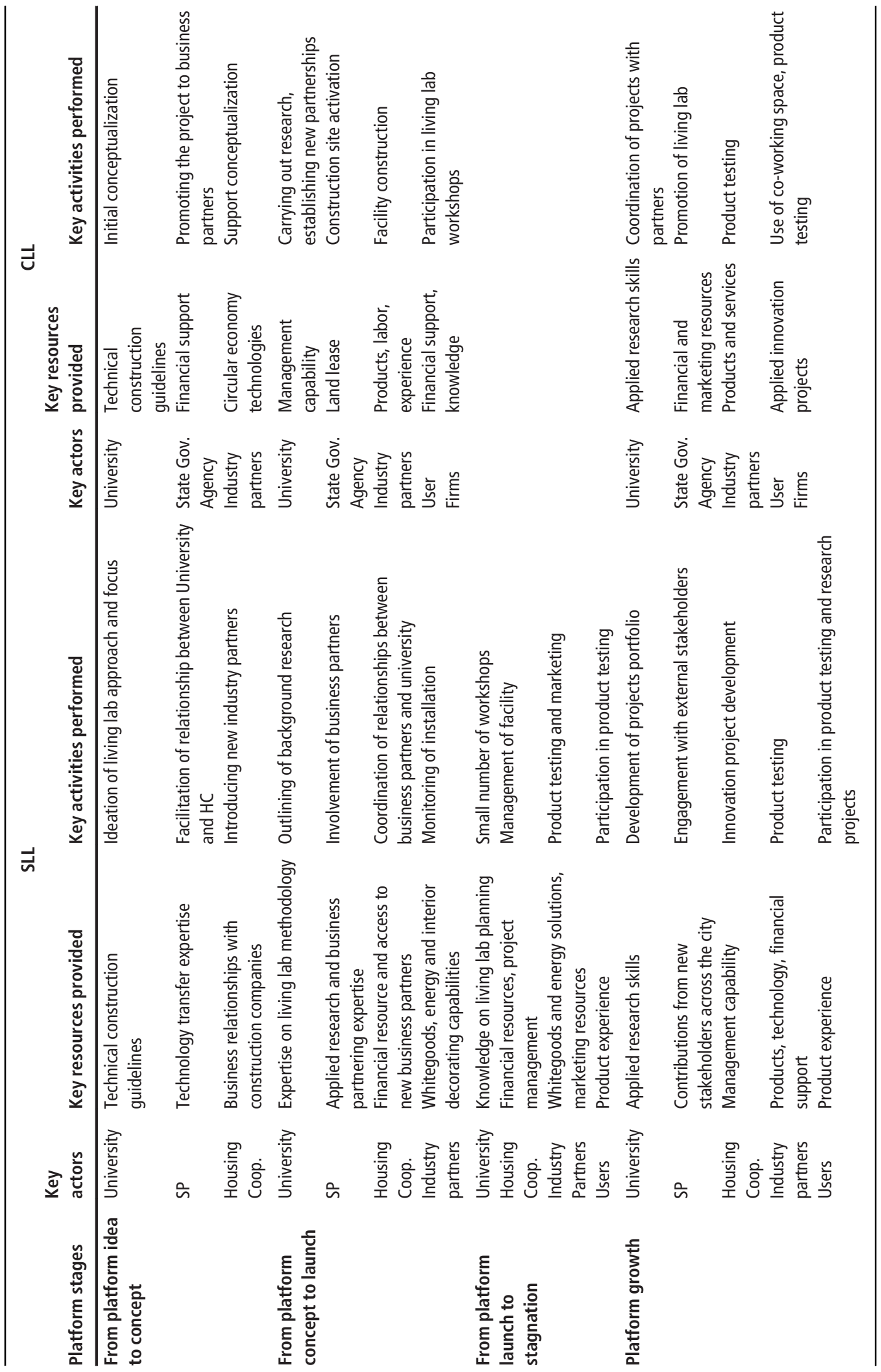




\section{Appendix 2}

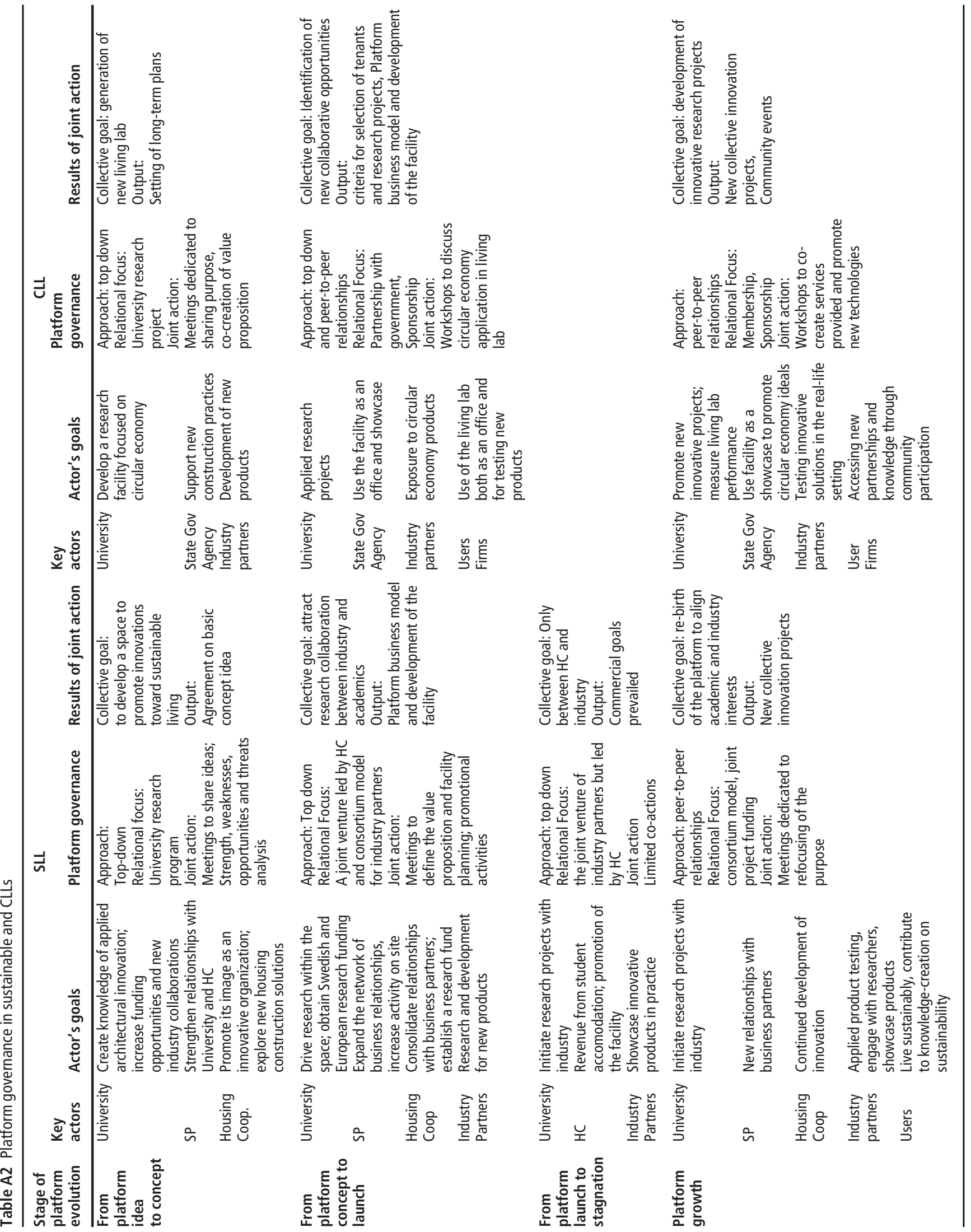

